\title{
FATORES DE RISCO EM DOENÇAS CEREBROVASCULARES - ESTUDO COM PACIENTES INTERNADOS NA CLÍNICA NEUROLÓGICA dO HOSPITAL DAS CLÍNICAS DA FACULdADE DE MEDICINA DA UNIVERSIDADE DE SĀO PAULO ENTRE 1977 e 1984*
}

\section{Eliane Corrêa Chaves**}

CHAVES, E.C. Fatores de risco em doenças cerebrovasculares: estudo com pacientes internados na clínica neurológica do Hospital das Clínicas da Faculdade de Medicina da Universidade de São Paulo entre 1977 e 1984. Rev. Esc. Enf. USP, São Paulo, 23(3):359-362, dez. 1989.

Este estudo teve como objeto de investigaçāo a doença cerebrovascular (DCV), algumas de suas caractertsticas epidemiologicas e a importancia da hipertensão arterial, das doenças cardtacas e do diabetes mellitus como fatores de risco para esta afeç̧ão cerebral.

UNITERMOS: Distúrbios cerebrovasculares. Epidemiologia. Enfermagem neurologica.

\section{INTRODUÇĀO}

Dentre as doenças que acometem mais freqüentemente os indivíduos de média idade ou idade avançada, as doenças cerebrovasculares representam em várias partes do mundo, importante causa de mortalidade, morbidade e invalidez, ocasionando sério problema social, econômico e de saúde ${ }^{2}$.

Apesar dos importantes avanços científicos nas áreas de neurofisiologia e fisiopatologia da DCV, nenhuma medida tem sido eficaz, no sentido de reduzir a dimensão do infarto cerebral uma vez ocorrido, ou de promover a regeneração do tecido nervoso infartado ${ }^{5}$. A prevenção surge, portanto, como a única conduta lógica e sensata no combate a estas afecçōes. As medidas preventivas apropriadas, no entanto, devem estar embasadas em estudos que analisem as circunstâncias sob as quais esta afecção tende a se instalar e a se desenvolver. Neste sentido a epidemiologia tem desempenhado um papel particularmente importante, pois ela se propōe entre outras coisas, a descrever de forma sistemática a história natural das

* Dissertação de Mestrado apresentada à Escola de Enfermagem da USP, 1986. (apresentação condensada).

** Enfermeira. Mestre em Enfermagem. Professor Assistente do Departamento de Enfermagem MédicoCirúrgica da Escola de Enfermagem da USP - disciplina Enfermagem Médico-Cirúrgica. 
diferentes doenças, determinar suas causas e os meios adequados para afastá-las da população ${ }^{1,3}$.

Ligados às investigaçōes epidemiológicas, encontram-se os estudos de risco, os quais referem-se à probabilidade que tem um indivíduo ou coletividade, de apresentar agravos à saúde ${ }^{6}$.

O risco em saúde sofre influência de diversos fatores denominados fatores de risco, os quais isolada ou associadamente tornam o indivíduo ou grupo por eles afetados, mais suscetíveis ao desenvolvimento ou agravamento de um determinado processo mórbido ${ }^{6}$.

Os fatores de risco são, na realidade, características que mantém relação significativa com um indesejado abalo no estado saúde-doença ${ }^{7}$.

No que diz respeito, particularmente às DCV, parece lógico que a presença de determinadas características pessoais ou ainda algumas condições mórbidas, principalmente as de caráter crônico, que comprometam direta ou indiretamente o sistema circulatório, possam aumentar a probabilidade dos indivíduos de desenvolverem as DCV.

Nesse sentido, têm sido mencionados como fatores de risco para a DCV, a hipertensão arterial, o diabetes mellitus, as doenças cardíacas, a hiperlipidemia, a obesidade, a utilização de contraceptivos orais, fatores hereditários, idade, estresse emocional e o padrão de personalidade 2,8 .

Várias pesquisas vêm sendo desenvolvidas pelos diferentes profissionais de saúde no sentido de determinar a veracidade e a importância destes fatores de risco nas diferentes populações. Neste sentido, acreditamos que é responsabilidade do enfermeiro, como membro da equipe de saúde, engajar-se neste processo de investigação dos fatores de risco da DCV, para posterior elaboração e implementação de programas de deteç̧ão e controle destes fatores. $O$ enfermeiro está, desta forma, contribuindo significativamente para a prevenção da DCV e de todas as suas conseqüências adversas.

O presente estudo teve os seguintes objetivos:

- investigar a proporção de pacientes com doenças cerebrovasculares internados numa clínica de um hospital geral, em relação a outros internados com afecções neurológicas diversas;

- pesquisar, entre os pacientes com DCV, a proporção de óbitc: em relação à sobrevida, a média de dias de internação, a proporção de seqüelas por eles apresentadas, os tipos de DCV mais freqüentes entre eles e a possível associação entre estas variáveis com o sexo e da idade;

- investigar a presença de alguns fatores de risco (hipertensão arterial, doenças cardíacas e diabetes meliitus) na história de vida pregressa da população estu- 
dada e a associação possível entre eles e as variáveis: dias de hospitalização, óbito, presença de seqüelas físicas, idade e sexo.

O presente estudo baseou-se em investigação retrospectiva realizada na Clínica Neurológica do Hospital das Clínicas da FMUSP e cuja fonte de informaçōes foram os 479 prontuários dos pacientes internados no período de $1^{\circ}$ de janeiro de 1977 a 31 de dezembro de 1984 e que tiveram como diagnóstico principal qualquer uma das afecções classificadas pelo Manual de Classificação estatística internacional da doença, lesōes e causas de óbito como doença cerebrovascular ${ }^{4}$.

\section{METODOLOGIA}

Para a coleta de dados foi utilizada uma ficha específica constituída basicamente em duas partes:

- a primeira onde foram registrados os dados de identificação, o diagnóstico principal, tempo de hospitalização, o destino após hospitalização, e a presença de seqüelas físicas.

- na segunda parte foram registradas informações sobre a presença de fatores de risco na população do estudo. Os fatores de risco investigados foram: a hipertensão arterial, o diabetes mellitus e as doenças cardíacas. Foi utilizado o teste de Qui quadrado para averiguar a existência de associação estatisticamente significante entre as variáveis do estudo.

\section{CONCLUSŌES}

Com os dados obtidos por meio desta conduta metodológica foi possível obter as seguintes conclusōes:

- entre 9 pacientes internados nesta clínica 1 possuía DCV como diagnóstico principal;

- a população estudada caracterizou-se como relativamente jovem, uma vez que a média de idade foi de 42,5 anos;

- houve discreto predomínio da quantidade de pacientes do sexo masculino sobre os do sexo feminino;

- os tipos de DCV mais freqüentes entre os pacientes estudados foram, em ordem de importância: os aneurismas das artérias cerebrais $(38,2 \%)$; os acidentes vasculares cerebrais isquêmicos $(27,1 \%)$ e os acidentes vasculares cerebrais hemorrágicos $(13,6 \%)$;

- a média de dias de internação dos pacientes estudados foi de 27 dias, sendo que $30,1 \%$ deles permaneceram hospitalizados por mais 30 dias;

- as seqüelas estiveram presentes em $64,2 \%$ dos sobreviventes; 
- a proporção de óbito em relação à sobrevida dos pacientes deste estudo foi de $1: 3$;

- a freqüência de altas diminuiu consideravelmente com a idade, ocorrendo o inverso em relação ao óbito;

- a freqüência de óbitos decresceu, à medida que o tempo de hospitalização aumentou e as altas tornaram-se mais freqüentes nas internações mais longas;

- dos pacientes estudados, $45,3 \%$ eram hipertensos, $18,6 \%$ cardíacos e $6,9 \%$ diabéticos, sendo que $52,1 \%$ dos hipertensos, $42,4 \%$ dos diabéticos e $66,3 \%$ dos cardiopatas ignoravam o fato de possuírem estas afecções;

- a freqüência de DCV nos pacientes que não possuíam os fatores de risco investigados decresceu com a idade; nos possuidores de pelo menos um fator de risco, a frequiência de DCV aumentou com a idade;

- 'os óbitos foram mais freqüentes nos pacientes com fatores de risco numa proporção aproximada de 2:1.

CHAVES, E.C. Risk factor in cerebrovascular disease - study with patients in ward of neurological clinic of "Hospital das Clínicas da Faculdade de Medicina da USP" from 1977 to 1984. Rev. Esc. Enf. USP, São Paulo, 23(3):359-362, dez. 1989.

The purpose of this research was the study of cerebrovascular disease (CVD), some of its epidemiological characteristics and the importance of high blood pressure, cardiac disease and diabetes mellitus as risk factors in this cerebral illness. sing.

UNITERMS: Cerebrovascular desordes. Epidemiology. Neurologic nur-

\section{REFEERÊNCIAS BIBLIOGRÁFICAS}

1. FORATTINI, O.P. Epidemiologia geral. São Paulo, Edgar Blucher, 1976.259 p.

2. LAVY, S. Medical risk factors in stroke. Adv. Neurol., New York, 25(12): 127-33, Nov. 1979.

3. LEAvELL, H.R. \& CLARK, E.G. Medicina preventiva. São Paulo, McGraw Hill, 1978.744 p.

4. ORGANIZAÇĀo MUNDIAL DA SAÚDE. Manual de classificação estatística internacional de doenças, lesōes e causas de óbito. Centro da OMS para Classificaçāo de Doenças em Português, 1978. v. 1 .

5. McDOWELL, F.H. Avaliação e controle do acidente vascular cerebral. Postgrad. Med., Minneapolis, 59(3): 3. Mar. 1976.

6. NOGUEIRA, M.J.C. Enfoque de risco na assistência de enfermagem comunitária. Trabalho apresentado no SIMPÓSIO SOBRE APLICAÇĀO DO ENFOQUE DE RISCO NA ASSISTÊNCIA DE ENFERMAGEM, São Paulo, 1984. 22 p. (mimeografado).

7. OJEDA, E.N.S. El enfoque de risco en la atencion perinatal y maternoinfantil. Bol. Of. Sanit. Panam., Washington, 92(6): 482-93, jun. 1982.

8. WESTER, P.O. Risk factors for stroke. Scand. J. Rehabil. Med., Stockholm, 7(suppl.): 6-10, Sept. 1980. 